\title{
Batalha do Sorriso: Processo de desenvolvimento de um jogo sério para a Saúde Bucal
}

\author{
Ariane N. Rodrigues, Hérikles V. F. Cordeiro, José Andersson S. da Silva, Ramon \\ E. Marques da Silva, Bruno Barboza dos Santos \\ Universidade de Pernambuco (UPE) campus Garanhuns - PE - Brasil \\ ariane.rodrigues@upe.br, \{heriklesvinicyuys, ramon.marques.upe @ @hotmail. \\ com, anderssonsoares97@gmail.com, bruno-barbozadoutlook.com
}

\begin{abstract}
This article describes the process of developing a serious game for Oral Health Education with steps based on the Design Thinking process. The steps are described in detail in addition to the techniques adopted to support the implementation of the game. The research advocates the importance of relating activities during the development process to design a playful solution with events that provide a fun learning experience. Ensuring that learning objectives can remain aligned to the playfulness of the game has been a major challenge in this context.
\end{abstract}

Resumo. Este artigo descreve o processo de desenvolvimento de um jogo sério para a Educação da Saúde Bucal com etapas baseadas nas do processo de Design Thinking. As etapas são descritas em detalhes, além das técnicas adotadas para apoiar a implementação do jogo. A pesquisa defende a importância em relacionar atividades durante o processo de desenvolvimento para conceber uma solução lúdica com eventos que proporcionem uma experiencia de aprendizagem divertida. Garantir que os objetivos de aprendizagem possam permanecer alinhados a ludicidade do jogo tem sido um grande desafio neste contexto.

\section{Introdução}

O uso das tecnologias na Educação é um tema recorrente nas discussões atuais. Com o desenvolvimento tecnológico e a necessidade da inclusão digital na escola, novas formas de aprendizado têm sido potencializadas com o uso de tecnologias digitais. De acordo com Silva e Gomes (2015), cenários de aprendizagem devem ser planejados para conceber novas situações didáticas, ricas de experiências, materiais e mídias. Planejar um cenário de aprendizagem requer contemplar o uso de tecnologias digitais em suas diversas possibilidades.

De acordo com Tchounikine (2013), a área "Technology Enhanced Learning” TEL (Aprendizagem Apoiada por Tecnologia - tradução nossa) relaciona discussões de diferentes perspectivas ao considerar como a aprendizagem pode ser melhorada pela adoção da tecnologia, de que forma as práticas educativas podem ser mudadas e como desenvolver um software educativo para um contexto pedagógico em específico. Para esta última perspectiva, Tchounikine (2013) destaca a contribuição da área de Computação pela possibilidade de conceber soluções de software por meio de modelos e processos de desenvolvimento. 
VII Congresso Brasileiro de Informática na Educação (CBIE 2018)

Anais dos Workshops do VII Congresso Brasileiro de Informática na Educação (WCBIE 2018)

Sob a perspectiva de implementação de soluções educativas, os cursos de Licenciatura em Computação também possuem como propósito formar profissionais aptos para o desenvolvimento de soluções tecnológicas para este contexto. De acordo com as Diretrizes Curriculares do MEC, o perfil esperado para o licenciando deve contemplar habilidades e competências para projetar e desenvolver softwares e hardware educacionais em equipes interdisciplinares. Neste caso, as atividades incluem, especificar os requisitos pedagógicos na interação humano computador, avaliar softwares e equipamentos para aplicação educacional e produzir materiais didáticos com a utilização de recursos computacionais para propiciar inovações nos produtos, processos e metodologias de ensino e aprendizagem.

Ao considerar o contexto de desenvolvimento de softwares educativos, este artigo apresenta o processo de desenvolvimento de um jogo sério para o contexto da Educação Bucal. Para Silva e Gomes (2015), um jogo sério é uma classificação de software educativo que visa primordialmente objetivos educacionais (ou de aprendizagem) alinhados ao entretenimento e a diversão.

Jogos sérios para a aprendizagem de ações relacionados a saúde bucal é importante porque há uma necessidade natural em envolver as crianças a ações simples para aprendizagem sobre cuidados pessoais. De acordo com o Referencial Curricular Nacional para a Educação Infantil (1998), o interesse progressivo ao próprio corpo com incentivo a aprendizagem de ações relacionadas à saúde e a higiene é um dos objetivos que deve ser promovidos. As recomendações é que estratégias ainda na escola possam ser planejadas para que as crianças possam desenvolver habilidades e construam conhecimentos sobre os cuidados com a boca. Neste caso destacam-se aprender os movimentos corretos para a escovação dos dentes e língua, além de aprender as funções dos materiais usados para a higiene oral.

Para os autores Silva e Gomes (2015) muitas críticas ainda são atribuídas a qualidade dos jogos sérios justamente por não atender as expectativas na aprendizagem, por manter uma fraca representação conceitual e desalinhamento aos objetivos pedagógicos. Esta pesquisa considera que a ludicidade e a interface são os elementos que devem ser amplamente discutidos pela equipe multidisciplinar e incluídos no processo de desenvolvimento de jogos sérios porque influenciam diretamente a aprendizagem. Segundo Mastrocola (2012) todo jogo possui um universo lúdico que potencialmente reúne um conjunto de propriedades que estimulam a diversão. Para representar os significados que influenciam a experiência de aprendizagem no contexto do jogo, implicações de design devem ser consideradas para ativar coerentemente processos cognitivos. Em suma, destaca-se que o processos de desenvolvimento de jogos apresentados na literatura pouco consideram atividades, durante a concepção do jogo, que possam relacionar a ludicidade e aprendizagem.

Este artigo está organizado em 4 seções. Além da introdução que contextualiza toda a pesquisa, a seção 2 relaciona pesquisas para fundamentação teórica sobre os processos de desenvolvimento de jogos sérios. A seção 3 e suas subseções apresentam detalhes do jogo Batalha do Sorriso, no que se refere aos seus objetivos, processo de desenvolvimento e suas etapas. Por fim, a seção 4 apresenta as conclusões iniciais da pesquisa.

\section{Referenciais Teóricos}


Há diferentes visões de como executar um processo de desenvolvimento de soluções educativas, particularmente, para os jogos sérios. Esta seção discute sobre pesquisas que indicam processos de desenvolvimento de jogos educativos.

De acordo com Murakami, Junior, Sabino e Macedo (2014), o processo de desenvolvimento de jogo sério pode ser definido conforme as etapas do Design Thinking (Imersão, Análise e Síntese, Ideação e Prototipagem). Para Cross (2011), o design thinking é um método para resolver problemas baseado em soluções, "pensandose". Em vez de se iniciar com um problema, inicia-se com uma solução-base e em seguida definem-se parâmetros para se atingir o objetivo final. No relato sobre o processo de desenvolvimento, os autores Murakami, Junior, Sabino e Macedo (2014) consideram atividades a cada etapa para favorecer a concepção do jogo e sua implementação. Percebe-se que as atividades focam em objetivos bem definidos de acordo as etapas, a exemplo da fase de análise e síntese, na qual o objetivo era reunir e compilar as informações elencadas na fase de imersão. A partir disso, montar um documento com o projeto do jogo e definir um quadro de atividades a serem realizadas.

Em Battistella (2014) um levantamento do estado da arte dos processos de desenvolvimento de jogos educacionais indica artigos que descrevem os processos de desenvolvimento dos jogos de forma detalhada, independente da área, a fim de localizar um processo de desenvolvimento amplamente aceito. Destacam-se os processos proposto por Staalduinen e Freitas (2011) por possibilitar seu uso para desenvolver um novo jogo, como traçar desempenho de aprendizagem com jogos. Sommeregger e Kellner (2012) apresentam um processo de 5 etapas: projeto conceitual, design do jogo, implementação, testes e avaliação. Além de deixar claro os objetivos das fases iniciais, como definir o público alvo.

Para Rocha (2015), além do processo de desenvolvimento e suas etapas, desafios associados a este processo também devem ser analisados. Os autores indicam a falta de descrição do ciclo de vida completo de desenvolvimento dos jogos sérios, onde muitos enfatizam áreas específicas. Ao comparar os processos de desenvolvimento dos autores, percebe-se que há uma superficialidade na concepção da ludicidade do jogo.

\section{Jogo Educativo Batalha do Sorriso}

Esta seção apresenta detalhes do jogo educativo que está sendo desenvolvido como projeto de Iniciação Científica do curso de Licenciatura em Computação da Universidade A. As etapas e atividades do processo de desenvolvimento também são descritas nas subseções desta seção.

\subsection{Objetivos de Aprendizagem}

De acordo com Tchounikine (2013), toda solução educativa é desenvolvida para atender objetivos. Os objetivos podem ser de aprendizagem ou pedagógicos, e são categorizados em principal e intermediário. Neste contexto, o jogo Batalha do Sorriso tem como principal objetivo favorecer a conscientização sobre os cuidados bucais. Como objetivos intermediários destacam-se a importância de envolver o estudante no contexto da limpeza em função de recursos para o cuidado com a saúde bucal, além de reforçar a necessidade das visitas periódicas ao dentista.

O autor Tchounikine (2013) ainda ressalta que, na concepção de um software educativo, é importante considerar que a implementação da solução deve refletir os 
VII Congresso Brasileiro de Informática na Educação (CBIE 2018)

Anais dos Workshops do VII Congresso Brasileiro de Informática na Educação (WCBIE 2018)

objetivos pedagógicos. Para fomentar a aprendizagem e orientar a implementação do jogo, objetivos de aprendizagem foram definidos tendo como base a Taxonomia de Bloom Revisada (Airaisan e Miranda, 2002). A taxonomia de Bloom revisada é uma estrutura de classificação para o domínio cognitivo que ajuda a formular declarações de aprendizagem, ou seja, o que se espera que os estudantes possam aprender a cada fase do jogo. A taxonomia de Bloom revisada foi escolhida porque orienta a classificação dos processos cognitivos (lembrar, entender, aplicar, analisar, avaliar e criar), além de relacioná-los a processos do conhecimento (efetivo, conceitual, procedural e metacognitivo). A Tabela 1 organiza os objetivos de aprendizagem, além de indicar sua relação com os processos do conhecimento.

Tabela 1. Objetivos de Aprendizagem do jogo Batalha do Sorriso

\begin{tabular}{|l|l|}
\hline \multicolumn{1}{|c|}{ Objetivos de Aprendizagem - OE } & \multicolumn{1}{|c|}{$\begin{array}{c}\text { Processo do } \\
\text { Conhecimento }\end{array}$} \\
\hline $\begin{array}{l}\text { OE1 - Lembrar dos produtos usados para a higienização bucal } \\
\text { reconhecendo a importância de cada um deles para a saúde. }\end{array}$ & Efetivo \\
\hline $\begin{array}{l}\text { OE2 - Entender a função de cada produto usado para a higienização bucal } \\
\text { interpretando sua função no combate das bactérias. }\end{array}$ & Conceitual \\
\hline $\begin{array}{l}\text { OE3 - Analisar e avaliar a situação da higiene bucal checando quais dos } \\
\text { produtos podem ser usados para tratar de cada problema bucal. }\end{array}$ & Procedural \\
\hline $\begin{array}{l}\text { OE4 - Criar estratégias para a higienização bucal planejando escolhas de } \\
\text { produtos adequados a cada problema ocasionado pelas bactérias. }\end{array}$ & Metacognitivo \\
\hline
\end{tabular}

A expressão "objetivos de aprendizagem" é usada nesta pesquisa para referenciar as habilidades cognitivas que podem ser adquiridas e/ou ativadas durante a interação com o jogo. Neste caso, as fases iniciais com os objetivo (OE1) reforçam o processo do conhecimento efetivo por considerar importante a aprendizagem de detalhes específicos aos produtos usados para a higienização bucal. As demais fases do jogo e seus objetivos (OE2, OE3 e OE4) relacionam processos do conhecimento conceitual, procedural e metacognitivo por enfatizar como e quando o estudante pode aplicar o conhecimento adquirido. $\mathrm{O}$ processo do conhecimento metacognitivo relaciona $\mathrm{o}$ conhecimento estratégico visto que o estudante precisa analisar a situação e escolher adequadamente os produtos que possam contribuir na higienização bucal $\mathrm{e}$ consequentemente combate as bactérias. Este processo do conhecimento estimula o estudante a pensar, para propor uma solução aos problemas bucais, a fim de proteger a boca dos ataques das bactérias.

\subsection{Processo de desenvolvimento do jogo}

Esta seção apresenta o processo de desenvolvimento definido para conduzir a implementação do jogo educativo Batalha do Sorriso. As etapas e suas atividades associadas são descritas em detalhes.

$\mathrm{Na}$ literatura, os processos de desenvolvimento de jogos educativos apresentam uma característica comum, um processo com etapas padrões para o desenvolvimento, aplicável a qualquer solução. Esta pesquisa critica os processos por pouco considerar atividades que possam definir a ludicidade do jogo em prol da aprendizagem. Para o game designer Túlio Soria (2015), os jogos com fins educacionais acabam se tornando chatos por focar exclusivamente em conteúdos, quando deveriam ser divertidos, 
VII Congresso Brasileiro de Informática na Educação (CBIE 2018)

Anais dos Workshops do VII Congresso Brasileiro de Informática na Educação (WCBIE 2018)

desafiantes e motivadores para construção do conhecimento. Por definição, segundo Silva e Gomes (2015), os jogos sérios ou educativos utilizam do prazer e da diversão para conseguir os objetivos de aprendizagem.

Neste contexto, esta pesquisa defende que o processo de desenvolvimento do jogo educativo deve ser iterativo e incremental, com etapas e atividades que possam favorecer a reflexão contínua para a resolução de problemas, inclusive os educacionais. O processo proposto para desenvolver o jogo é composto por seis etapas baseadas nas quatro fases básicas do design thinking: imersão, análise e síntese, ideação e prototipagem. A Figura 1 apresenta o processo de desenvolvimento usado para desenvolver o jogo educativo Batalha do Sorriso.

\section{Imersão \Análise >Ideação >Prototipagem ymplementação Validação}

Figure 1. Etapas do processo de desenvolvimento

Para cada etapa do processo de desenvolvimento foram adotadas técnicas de design e da área da Computação que pudessem apoiar a implementação do jogo. Para Tchounikine (2013) e Silva e Gomes (2015), o grau de complexidade associado a elaboração de jogos sérios requer uma equipe multidisciplinar. Inclusive, para o contexto desta pesquisa, um especialista da área de Odontologia seria necessário porque é o profissional que domina o assunto do qual o jogo retrata. Neste caso, a equipe era formada por três estudantes de Licenciatura em Computação para implementar o jogo, um docente com formação em Computação para orientar a execução do processo de desenvolvimento e um profissional da área de Odontologia para alinhar o conteúdo com a dinâmica do jogo para atender os objetivos de aprendizagem.

A primeira etapa do processo é a de imersão. Ela representou o momento no qual a equipe precisou entender o contexto e o tema do jogo educativo. Esta etapa é de extrema importância porque favorece o entendimento e alinhamento da equipe. A principal preocupação era de entender como conceber um jogo divertido para favorecer a aprendizagem e a experiência de forma lúdica. Nesta etapa, diversas informações acerca do contexto foram obtidas por meio de pesquisas na literatura. Para incentivar a equipe a pensar e discutir sobre o problema de como conceber a ideia do jogo, o modelo de resolução de problemas proposto por Delisle (1997) foi adotado. O modelo de Delisle possui quatro etapas (1 - Ideias; 2 - Fatos; 3 - Hipóteses; e 4 - Plano de Ação) e permite organizar informações para a tomada de decisão inicial no processo de resolução. Para facilitar a condução da dinâmica, os estudantes deveriam discutir e definir respostas aos questionamentos refletidos pelas etapas: "1- Quais ideias tivemos para implementar o jogo?"; "2 - Quais informações relevantes acerca do contexto do jogo aprendemos?"; "3 - O que precisamos investigar sobre o contexto para implementar o jogo? "; "4 - Quais estratégias, recursos e responsabilidades adotaremos para solucionar o problema?". Ao final da dinâmica, com os conhecimentos melhor refinados, a equipe seguiu para a etapa de análise e síntese.

A etapa de análise e síntese no processo de desenvolvimento teve como objetivo refinar as informações da etapa de imersão, além de sistematizar a pré concepção do jogo. Uma atividade importante nesta etapa foi a de análise competitiva. Esta atividade faz parte do conjunto de atividades da Engenharia de Usabilidade proposta por Jakob 
Nielsen, na área de Interação Humano Computador (Barbosa e Silva, 2010). Seu propósito é permitir que produtos com funcionalidades semelhantes possam ser examinados para que funcionalidades e características desejáveis pudessem inspirar a implementação do produto desta pesquisa. Neste caso, jogos educativos no contexto da saúde bucal foram selecionados da literatura. Como resultado, percebeu-se que muitos dos jogos neste contexto adotam mais estratégias para uma aprendizagem baseada na memorização com associações. Em Dotta, Campos e Garcia (2012), por exemplo, é apresentado um jogo com associação entre desenhos, jogo da memória e jogo de pintar para abordar conceitos básicos acerca da placa dental bacteriana, como sua formação e principais doenças. Métodos de higiene bucal com ênfase na cárie dental também é considerado. Também foram encontradas pesquisas que detalham a concepção de jogos físicos, como em Ferraz et. al (2008), que apresentam o jogo de memória com cartas explicativas sobre cuidados com a higiene bucal. Em Pelleti (2015), destaca-se o "Micro Dentista" como um jogo de aventura focado em ações como pular e atirar para eliminar as bactérias. Em síntese, esta pesquisa defende que estas estratégias limitam a aprendizagem porque não incentivam o estudante a refletir. Isso porque os jogos mantém o foco na movimentação dos personagens, na eliminação dos inimigos, ou até mesmo na posição dos elementos (para jogos da memória). Idealmente, os jogos para este contexto, precisam estimular a tomada de decisão onde é necessário pensar como resolver o problema inerentes a higienização bucal.

A terceira etapa do processo é a de ideação, momento propício para estimular o pensamento criativo da equipe para idealizar os elementos essenciais ao jogo. Nesta etapa, a técnica de brainstorm e a ferramenta Game Model Canvas foram adotadas para guiar as definições e refinamentos das ideias discutidas nas etapas anteriores. O Game Model Canvas é uma estrutura composta por 13 blocos que especificam detalhe acerca dos elementos do jogo com os personagens, suas ações, os recursos e cenários, entre outros detalhes específicos a aplicação. O jogo Batalha do Sorriso tem inspiração para a sua jogabilidade em um tower defense chamado Plants vs. Zombie. No jogo Plants vs. Zombie, o jogador possui a missão de defender a casa da invasão de diferentes tipos de zumbis. Com lógica similar, para o Batalha do Sorriso, o jogador precisa defender sua boca da invasão de bactérias oriundas de problemas da saúde bucal. O player está na pele de uma menina em fase de troca dos dentes, no momento da visita de rotina ao dentista. A Figura 1 apresenta a comparação de cenários entre os jogos.
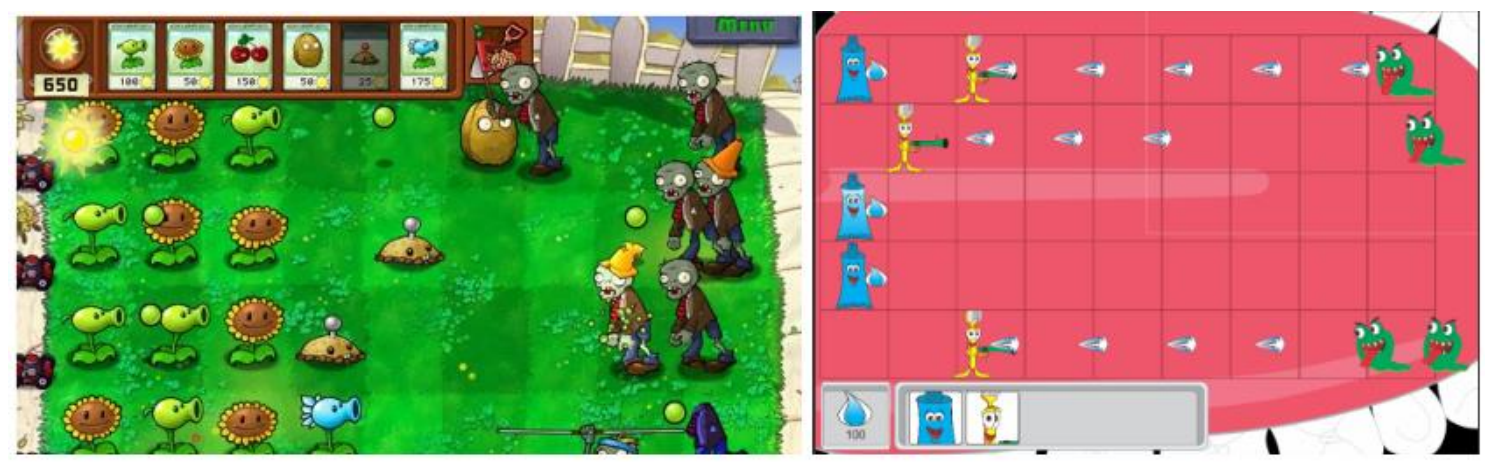

Figure 2. Cenário do Plants vs. Zombie e do jogo Batalha do Sorriso.

Como pode ver na Figura 1, o cenário do jogo Batalha do Sorriso representa o interior de uma boca com evidência para a língua, com a propósito de eliminar as bactérias que 
VII Congresso Brasileiro de Informática na Educação (CBIE 2018)

Anais dos Workshops do VII Congresso Brasileiro de Informática na Educação (WCBIE 2018)

causam cáries, mau hálito e outras infecções. Para realizar a defesa, o jogador deve gerenciar os recursos que são os produtos de higienização mais usados: Limpador de Língua, Creme Dental, Escova de Dentes, Fio Dental, Enxaguante Bucal.

O aspecto lúdico do jogo foi bastante discutido nesta etapa. Para Mastrocola (2012), os jogos são representações de uma realidade paralela. Neste mesmo sentido, Huizinga (2001), defende que o jogo representa alguma coisa que possui significado, gera experiências para aqueles que estão imersos em sua realidade não "real". É como um intervalo em nossa vida cotidiana, como um mundo mágico (círculo mágico) com eventos especiais e leis próprias. Neste definição, o círculo mágico do jogo é a boca e esboça uma relação direta com a realidade por considerar a necessidade em realizar diariamente cuidados pessoais. Ao imergir no mundo mágico do jogo, o estudante deve aprender que existem diferentes bactérias e que há formas variadas de combatê-las. A ludicidade está na possibilidade de transformar um evento normal do mundo real, como o ato de escovar os dentes, por exemplo, em um evento especial. Neste caso, os personagens definidos para o jogo possuem características diferentes e quando ativados realizam suas funções de forma especial. A Tabela 2 apresenta detalhes das características e eventos especiais associados aos personagens.

Tabela 2. Detalhes dos personagens do jogo

\begin{tabular}{|c|c|c|}
\hline Personagem & Função & Evento Especial \\
\hline $\begin{array}{l}\text { Limpador de } \\
\text { Língua }\end{array}$ & $\begin{array}{l}\text { Defesa: remove todas as bactérias na linha } \\
\text { que foi ativado. }\end{array}$ & $\begin{array}{l}\text { Deixa um rastro luminoso na } \\
\text { linha que foi ativado. }\end{array}$ \\
\hline Creme Dental & $\begin{array}{l}\text { Produtor: produz créditos para liberar } \\
\text { novos aliados }\end{array}$ & Aumento de brilho gradativo \\
\hline Escova & $\begin{array}{l}\text { Defesa: atira creme dental, usado para } \\
\text { atacar a distância. }\end{array}$ & Tiros coloridos com poder \\
\hline Fio dental & $\begin{array}{l}\text { Defesa: manter uma barreira temporária } \\
\text { para deter os inimigos por um curto espaço } \\
\text { de tempo. }\end{array}$ & $\begin{array}{l}\text { O fio ficará brilhante como } \\
\text { uma energia. }\end{array}$ \\
\hline $\begin{array}{l}\text { Enxaguante } \\
\text { bucal }\end{array}$ & $\begin{array}{l}\text { Defesa: explode os inimigos dos quadrantes } \\
\text { vizinhos }\end{array}$ & $\begin{array}{l}\text { Os quadrados atingidos } \\
\text { ficam brilhando para } \\
\text { representar o efeito de } \\
\text { limpeza. }\end{array}$ \\
\hline Super Dente & $\begin{array}{l}\text { Defesa: remover todos os inimigos da } \\
\text { língua. }\end{array}$ & Poderoso flash \\
\hline $\begin{array}{l}\text { Cárie } \\
\text { "Streptococcus } \\
\text { Mutans 01" }\end{array}$ & Ataque: Ataca os defensores com mordidas. & $\begin{array}{l}\text { Deixa rastro que facilita a } \\
\text { locomoção de outra bactéria }\end{array}$ \\
\hline $\begin{array}{l}\text { Placa } \\
\text { "Streptococcus } \\
\text { Mutans 02" }\end{array}$ & Ataque: Ataca os defensores com mordidas. & $\begin{array}{l}\text { Ao tocar um defensor, o } \\
\text { congela por um curto tempo, } \\
\text { enquanto o morde. }\end{array}$ \\
\hline
\end{tabular}

Para os personagens inimigos, representados pelas bactérias, um mapeamento foi realizado para estabelecer categorias de poder, identificar características para relacionar seu impacto no jogo. A Tabela 3 apresenta detalhes das bactérias em relação as categorias fraco, intermediário e forte. É importante reforçar que o resultado do mapeamento e a definição dos impactos também foi discutida com o profissional de Odontologia. 
VII Congresso Brasileiro de Informática na Educação (CBIE 2018)

Anais dos Workshops do VII Congresso Brasileiro de Informática na Educação (WCBIE 2018)

Tabela 3. Detalhes das bactérias como personagens inimigos no jogo.

\begin{tabular}{|l|l|c|}
\hline Categorias & \multicolumn{1}{|c|}{ Impactos } & Personagem \\
\hline Fraco & $\begin{array}{l}\text { Representa uma pequena parcela da flora bacteriana. Tem } \\
\text { como característica, a menor agressividade quando age de } \\
\text { forma solitária. }\end{array}$ & COCCUS \\
\hline Intermediário & $\begin{array}{l}\text { Tem danos a saúde bucal menos significativos quando estão } \\
\text { sozinhos. São mais oportunistas, suas ações só geram danos } \\
\text { graves ao agirem se aproveitando de danos inicializados por } \\
\text { outras bactérias. }\end{array}$ & LACTO \\
Forte & $\begin{array}{l}\text { Os personagens que integram esta categoria são de grupos } \\
\text { variados de bactérias. De forma resumida, seus impactos são } \\
\text { mais agressivos desde o início, sendo algumas causadoras de } \\
\text { danos em todo o sistema digestivo. }\end{array}$ & $\begin{array}{c}\text { STREP } \\
\text { PLANCTO } \\
\text { MUTANO } \\
\text { COLI }\end{array}$ \\
\hline
\end{tabular}

A ludicidade do jogo é fortemente representada pelos eventos especiais associados aos personagens. Além dos eventos apresentados na Tabela 2, destacam-se também como evento especial "a chuva de açúcar" como efeito "de neve" discutido para representar a relação da alimentação com os problemas bucais. O consumo em excesso de açúcares é um dos principais inimigos dos dentes e saúde bucal. Tal fato ocasiona buracos nos dentes, influenciando o surgimento das cáries. Importante também relacionar que as doenças bucais são causadas por espécies diferentes de bactérias, que em sua maioria, utilizam os açúcares como alimento.

Uma vez concebida toda a ideia do jogo, uma versão inicial do produto foi desenhada à mão, durante a etapa de prototipagem. A Figura 3 apresenta os personagens aliados a higienização, representados pelos produtos para a limpeza bucal e os inimigos, representados pelas bactérias.

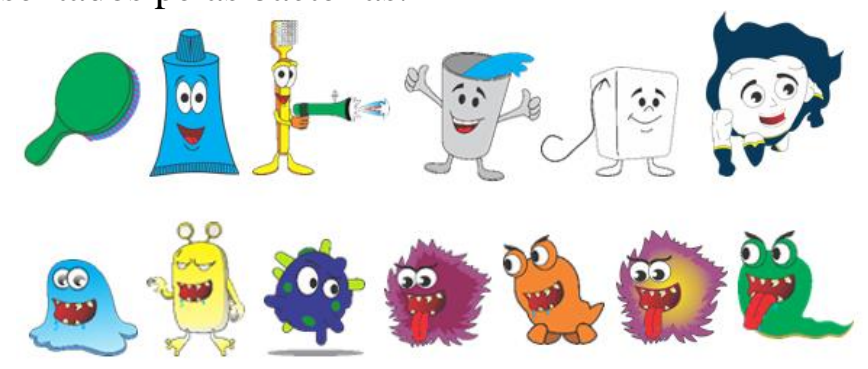

Figura 3. Personagens do jogo.

Os protótipos dos personagens foram refinados ao longo do desenvolvimento do jogo. As representações gráficas foram definidas com implicações de design para ativar processos cognitivos como atenção, percepção, memória e o aprendizado. A Figura 4 apresenta a tela inicial do jogo e a tela da fase inicial. 


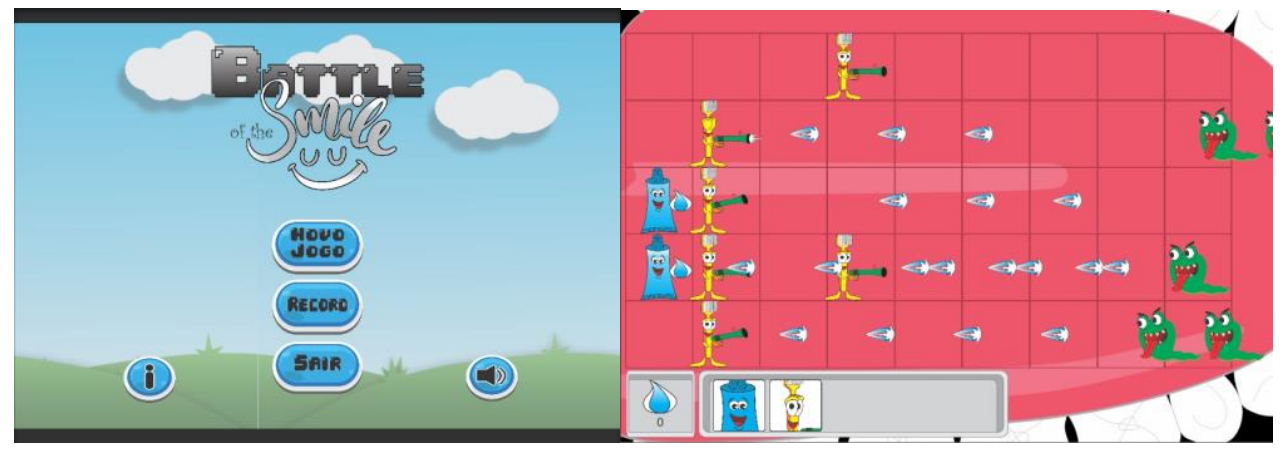

Figura 4. Telas do jogo

Por sua vez, a etapa de implementação envolve a escolha da ferramenta para o desenvolvimento. Neste caso, a Unity 5 foi escolhida como plataforma para construção deste jogo, pois, apresenta uma proposta de motor gráfico para jogos de animação $2 \mathrm{D}$ e 3D. Os recursos desta versão permitem desenvolver vários aspectos do jogo, como toda a movimentação dos personagens e toda sua dinâmica. Outro motivo paara a escolha do Unity, diante dos demais motores gráficos, foi o da facilidade de portar a mesma aplicação para várias plataformas, sem que necessite de alterações no jogo, além deter uma vasta documentação e material de consulta para tirar dúvidas que possam aparecer durante a implementação.

Por fim, a etapa de validação no processo tem como propósito favorecer as melhorias do jogo, tanto no que se refere aos seus aspectos de aprendizagem, quanto da dinâmica do jogo em si. A atividade de testar o jogo ao envolver potenciais usuários reais deve ser planejada porque os resultados torna-se essencial para avaliar e evoluir aspectos que influenciam diretamente na aprendizagem com o jogo.

\section{Considerações Finais}

O jogo Batalha do Sorriso é um produto de software para a educação da saúde bucal desenvolvido com apoio de pesquisas acadêmicas referente ao projeto de Iniciação Cientítica. É importante considerar que o projeto está em andamento e por isso este artigo não apresenta resultados de sua aplicabilidade. Como atividades futuras, planejase a conclusão da implementação do jogo, além de sua aplicação em contextos reais.

Por se tratar de solução educativa, espera-se como principal resultado, favorecer a aprendizagem de maneira divertida. O projeto permite aos estudantes de Licenciatura em Computação refletir sobre um problema real no contexto da aprendizagem na educação infantil assim como conceber uma solução tecnológica por meio da pesquisa, planejamento e programação de jogos sérios. Neste processo, os estudantes envolvidos podem adquirir novas experiências em processos de desenvolvimento de softwares, lidar com situações reais. Neste caso, envolve a interação com profissionais de ensino e/ou profissionais com formação em Odontologia, ter expertise para filtrar as informações e transformar em requisitos para o desenvolvimento da solução, usar lógica e técnicas de programação, além de aplicar a solução com usuários reais para evoluir e verificar sua qualidade.

\section{References}

"E se a aula fosse divertida como um game?" Revista Educatrix https://www.moderna.com.br/educatrix/ed10/educatrix10.html?pag=66 
VII Congresso Brasileiro de Informática na Educação (CBIE 2018)

Anais dos Workshops do VII Congresso Brasileiro de Informática na Educação (WCBIE 2018)

Airasian, P. W.; Miranda, H. (2002) "The Role of Assessment in the Revised Taxonomy".

Barbosa, S. D. J.; Silva, B. S. (2010) “Interação Humano-Computador”. Editora Campus-Elsevier.

Cross, N. (2011) "Design Thinking: Understanding how designers think and work". Nova Iorque.

Delisle, R. (1997) "How to Use Problem-Based Learning in the Classroom". Alexandria, VA: Association for Supervision and Curriculum Development.

Ferraz, J.R. e Mialhe, F.L. e Gonçalo, C.D.S (2017). "Aprendizado em saúde bucal por meio de um jogo educativo". Revista Uningá, 15(1).

Huizinga, J. (2001) "Homo ludens”. São Paulo: Perspectiva.

Mastrocola, V. M. (2012) "Ludificador: um guia de referências para o game designer brasileiro." São Paulo: Independente.

Murakami, L. C.; Júnior. A. J. M. L.; Sabino. R. F. S.; Macedo. D. A. (2014). "Design Thinking como metodologia alternativa para o desenvolvimento de jogos sérios" XIX Conferência Internacional sobre Informática na Educação - TISE.

Peletti, R.B. (2015) “Micro Dentista: Um Jogo Digital Aplicado a Saúde Bucal”. SBC Proceedings of SBGames 2015.

Referencial Curricular Nacional para a educação infantil/Ministérios da Educação e do Desporto, Secretarua de Educação Fundamental - Brasília: MEC (1998), http://portal.mec.gov.br/seb/arquivos/pdf/volume2.pdf.

Rocha. R. V.; Bittencourt. I. I.; Isotani. S. (2015). “Análise, Projeto, Desenvolvimento e Avaliação de Jogos Sérios e Afins: uma revisão de desafios e oportunidades" XXVI Simpósio Brasileiro de Informática na Educação - SBIE 2015.

Silva, A. C. B. da, Gomes, A. S. (2015) "Conheça e utilize software educativo: avaliação e planejamento para a educação básica”, Pipa Comunicação.

Sommeregger, P.; Kellner, G. (2012). "Brief Guidelines for Educational Adventure Games Creation". Digital Game and Intelligent Toy Enhanced Learning, IEEE 4th Int. Conf., Takamatsu, Japão, p. 120-122.

Staalduinen, J. v. e Freitas, S. (2011). “A Game-Based Learning Framework: Linking Game Design and Learning Outcomes" Nova York: Peter Lang, p. 29-45.

Tchounikine, P. (2011) "Computer Science and Educational Software Design. A resource for Multidisciplinary Work in Technology Enhanced Learning". 